\title{
Aneurysm formation after paclitaxel-eluting balloon angioplasty used to treat coronary artery restenosis after plain old balloon angioplasty - case report and review of the literature
}

\author{
Dobrin Vassilev ${ }^{1}$, Kiril Karamfiloff ${ }^{1}$, Robert Gil $^{2,3}$ \\ ${ }^{1}$ Department of Cardiology, “Alexandrovska” University Hospital, Medical University, Sofia, Bulgaria \\ ${ }^{2}$ Central Clinical Hospital of the Internal Affairs and Administration Ministry, Warsaw, Poland \\ ${ }^{3}$ Institute of Experimental and Clinical Medicine, Polish Academy of Science, Warsaw, Poland
}

Postep Kardiol Inter 2015; 11, 3 (41): 250-251

DOI: $10.5114 /$ pwki.2015.54027

\section{Introduction}

We report the first case of coronary aneurysm formation after paclitaxel-eluting balloon angioplasty (PEBA) used to treat a coronary restenosis following previous balloon angioplasty.

\section{Case report}

A 58-year-old man with a history of arterial hypertension, dyslipidemia and active smoking was admitted to our institution in September 2011 for recurrent angina after previous plain old balloon angioplasty (POBA) in the left anterior descending artery 3 months previously (Figure $1 \mathrm{~A}, \mathrm{~B}$ ). During the previous hospitalization, reduced left ventricular ejection fraction (32\%), septo-apical aneurysm and apical thrombosis were found. The decision about POBA (and eventual bare metal stenting) was due to the need of oral anticoagulation, double antiplatelet therapy, small caliber of the reference vessel, high CRUSADE Bleeding Risk Score, and history of pyloric stenosis and traumatic subdural hematoma. There was a high-grade restenosis in the previously treated segments. A decision was made for repeated angioplasty with a drug-eluting balloon (DEB) (because of long-term risk from bleeding still deemed high for prolonged antithrombotic therapy after drug-eluting stent implantation and high risk of restenosis). Both lesions were predilated $(2.5 \times 20 \mathrm{~mm}$ semi-compliant balloon up to $8 \mathrm{~atm})$. A $2.75 \times 20 \mathrm{~mm}$ paclitaxel-eluting balloon (Dior, Eurocor $\mathrm{GmbH}$, Germany) was inflated at $8 \mathrm{~atm}$ for $30 \mathrm{~s}$ in the distal lesion and the same balloon was then inflated to
10 atm for another 30" in the proximal lesion. The final angiographic result was good and the patient was scheduled for angiographic follow-up after 3 months (routine at our institution for all patients treated with drug-eluting balloons).

The patient came back to our department at the end of January 2012. A non-significant restenosis of the distal lesion and no restenosis of the proximal lesion were present. However, the angiogram revealed a coronary aneurysm in the distal segment, at the site of the first inflation of the DEB (Figure $1 \mathrm{C}, \mathrm{D}$ ). Both the angiogram and the echocardiogram of the left ventricle of the patient showed persistent septo-apical aneurysm, but with no signs of intracavitary thrombus. He was discharged on the following day and left on triple antithrombotic therapy for the next 3 months and then was advised to take double antiplatelet therapy for 6 more months (as the ischemic risk from local aneurysm thrombosis was considered as high).

\section{Discussion}

To the best of our knowledge, this is the first report of coronary artery aneurysm formation after PEBA of coronary artery restenosis following POBA. Coronary aneurysm formation is well recognized after stent implantation, and is observed much more frequently after DES implantation than after bare metal stent (BMS) implantation [1]. In our case, we used a second generation paclitaxel-eluting balloon (Dior, Eurocor GmbH, Germany). It uses a new technology utilizing a $1: 1$ mixture of paclitaxel and shellac, with a paclitaxel concentration

\section{Corresponding author:}

Kiril Karamfiloff, Department of Cardiology, “Alexandrovska” University Hospital, Medical University, 1 Georgi Sofiiski St, 1794 Sofia, Bulgaria, fax: +359 887369766 , e-mail: organic@abv.bg

Received: 17.02 .2015 , accepted: 12.04 .2015$. 

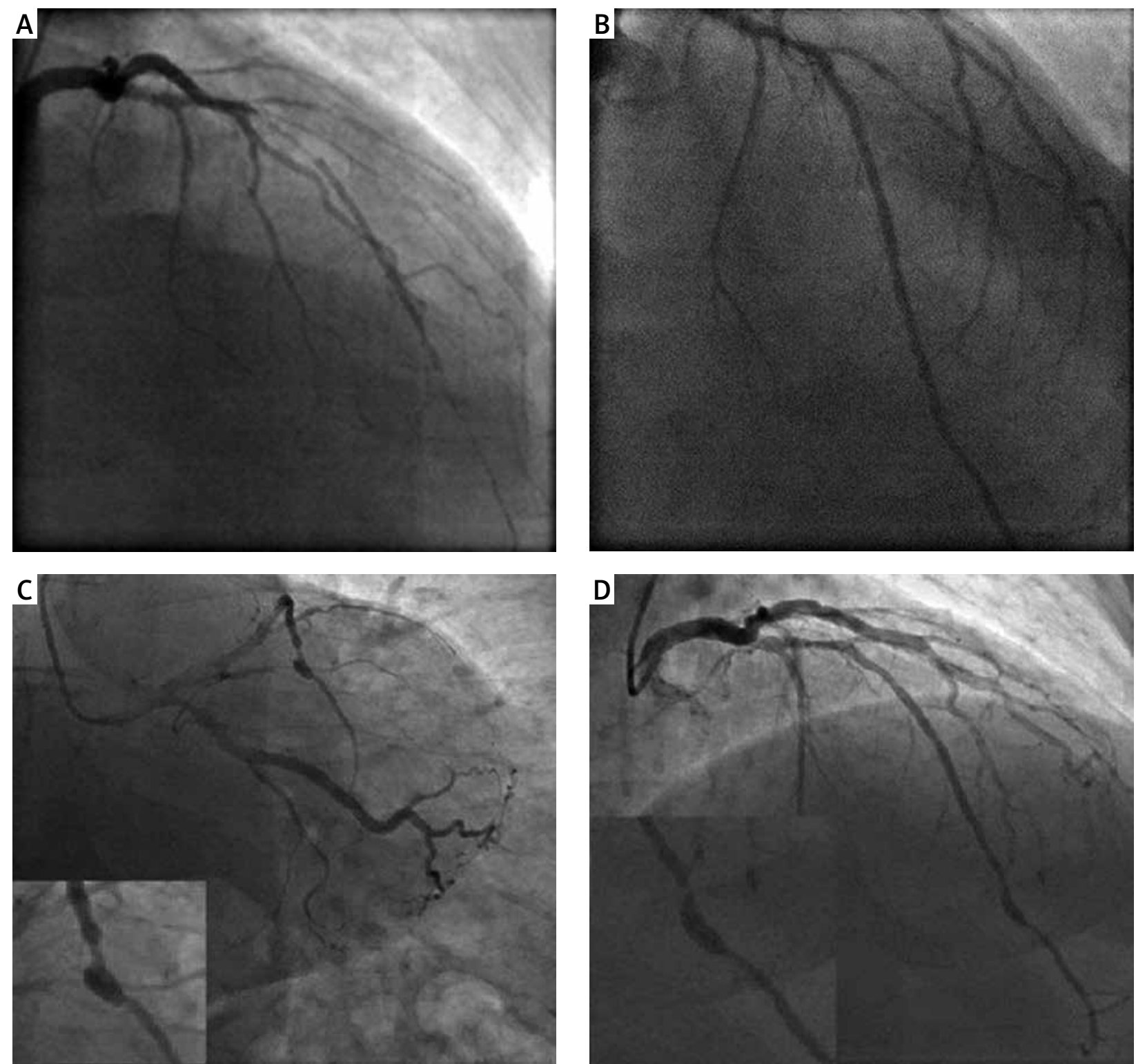

Figure 1. A - Initial angiogram from June 2011 - critical LAD stenosis in the mid and distal segment of the vessel. B - Angiography from September 2011 - final result (AP cranial view). C, D - Angiogram performed by the end of January 2012: a coronary aneurysm is seen in the distal LAD segment (AP caudal and RAO cranial views)

of $3.0 \mu \mathrm{g} / \mathrm{mm}^{2}$. It is possible that high concentrations of paclitaxel in combination with repetitive vessel trauma from several balloon inflations could be the cause of aneurysm formation. Our case raises the question of DEB safety, especially in off-label application.

We preferred a conservative approach, as previously reported in cases with coronary aneurysms induced after DEB application for BMS/drug-eluting stent (DES) restenosis [2, 3].

\section{Conflict of interest}

The authors declare no conflict of interest.

\section{References}

1. Aoki J, Kirtane A, Leon MB, Dangas G. Coronary artery aneurysm after drug-eluting stent implantation. J Am Coll Cardiol Intv 2008; 1: 14-21.

2. Kovarnik T, Mintz GS, Sonka M. The late stent malapposition develops also after paclitaxel balloon predilatation before bare-metal stent implantation: case description. Eur Heart J 2011; 32: 1432.

3. Vassilev D, Hazan M, Dean L. Aneurysm formation after drug-eluting balloon treatment of drug-eluting in-stent restenosis: first case report. Cathet Cardiovasc Interv 2012; 80: 1223-6. 